\title{
Trust, Sexual Trust, and Sexual Health: An Interrogative Review
}

\author{
J. Dennis Fortenberry \\ Department of Pediatrics, Indiana University School of Medicine
}

\begin{abstract}
Trust is experienced almost constantly in all forms of social and interpersonal relationships, including sexual relationships, and may contribute both directly and indirectly to sexual health. The purpose of this review is to link three aspects of trust to sexual health: (1) the role of trust in sexual relationships; (2) the role of trust in sexually transmitted infection (STI) prevention, particularly condom use; and (3) the relevance of trust in sexual relationships outside of the traditional model of monogamy. The review ends with consideration of perspectives that could guide new research toward understanding the enigmas of trust in partnered sexual relations in the context of sexual and public health.
\end{abstract}

This is the author's manuscript of the work published in final form as:

Fortenberry, J. D. (2019). Trust, Sexual Trust, and Sexual Health: An Interrogative Review. Journal of Sex

Research, 56(4-5), 425-439. https://doi.org/10.1080/00224499.2018.1523999 
Trust is closely associated with sexual relationships and the sexual content of those relationships but is neither necessary nor sufficient for either. Trust appears to be both antecedent and consequence of sex, and violations of sexual trust distort the comfort and safety of many relationships. Trust, it seems, has many contradictions. The purpose of this review, then, is to address three specific areas linking aspects of trust to sexual health and well-being: (1) the role of trust in sexual relationships; (2) the role of trust in sexually transmitted infection (STI) prevention, particularly in terms of intrarelationship condom use; and (3) the relevance of trust in sexual relationships outside of the traditional model of monogamy.

The intellectual genesis of the review began in the early 1980s, toward the beginning of my career focused in adolescent sexuality research and, coincidentally, at the beginning of the worldwide epidemics of human immunodeficiency virus (HIV) infections and consequent resurgence of interest in infection prevention with condoms (Amy \& Thiery, 2015). A prevalent paradigm of the era framed adolescent sexual behavior in terms of the public health challenges of "epidemics" of early and unintended pregnancy (National Research Council, 1987). Consequently, this pervasive paradigm was almost exclusively heteronormative and mononormative, emphasizing adolescent sexual behavior as "premarital" or "nonmarital" (Christopher \& Cate, 1988). In this historical context, the social, political, and public health discourses about adolescent sexuality included widely applied theoretical perspectives that associated young people's sexual behaviors with delinquency (Reiss, 1970), as part of a syndrome of “problem behaviors” reflecting psychosocial unconventionality (Jessor \& Jessor, 1977), and as a developmentally inevitable propensity to "risk taking” (Philliber, Namerow, Kaye, \& Kunkes, 1986). Some of my early research reflected this larger social and professional anxiety about adolescent sexual behavior (Costa, Jessor, Donovan, \& Fortenberry, 1995; Costa, Jessor, Fortenberry, \& Donovan, 1996). Trust was seldom, if ever, mentioned as a component of young people's decisions and behaviors in their sexual relationships.

My interest in sexual trust emerged, then, after many clinical conversations with young people about their sexual relationships. A modal response to my inquiry about condom use was "We used to, but now we 
trust each other." In fact, my research team later showed that the interval and the number of within-dyad coital events until condom use ceased was about 21 days (Fortenberry, Tu, Harezlak, Katz, \& Orr, 2002) and nine coital events (He, Hensel, Harezlak, \& Fortenberry, 2016). Condomless (called "unprotected" in those days) sex justified by such relatively rapid discovery of "trust" made no clinical sense in the context of the prevalence of pregnancies and incurable STIs. My patients' dependence on trust—rather than condoms - amplified a frustrated cynicism that trust was a threat to individual and public health (Civic, 1999). The uniformly fatal HIV infections of the mid-1980s, in particular, heightened a prevailing sense of the dangers of sex, and the naivete of trust-based decisions to forgo condoms (Hein, 1992).

Fortunately for me, the repetitively heard story about condomless sex eventually stimulated more attuned listening to the relationship stories of my patients and guided a more thoughtful interrogation of the reasons relationship and sexual trust mattered so much. I began to understand a richer story about sexual relationships where trust functioned as an endorsement of intimacy ideals of sex that motivated sex in the first place and modeled a love-based, companionate sexuality rooted in social models of monogamy that also justified nonmarital sex (Lear, 1995; Michael, 2003). Monogamy was, and remains, a centerpiece of public health approaches to STIs, including HIV (Gostin, 2013; Kelly \& Kalichman, 1995). Now, however, the great span of contexts of the experiences of normative sex have fully exposed the limits of monogamy (as an ideal for sexual relationships and as public health policy) (Balzarini, Shumlich, Kohut, \& Campbell, 2018; Conley, Matsick, Moors, Ziegler, \& Rubin, 2015). The historical moment thus seems appropriate for more in-depth interrogation of trust and sexual trust in relation to sexual health and wellbeing.

\section{A Discursive Definition of Sexual Trust}

Trust research has extraordinarily broad intellectual origins in diverse fields such as philosophy, sociology, social psychology, behavioral economics, political science, and neurobiology, among others. The interplays of trust, trustworthiness, and distrust form a critical emotional and cognitive infrastructure for all forms of political, economic, work, social, and interpersonal relationships (Butler, 1986; 
Mikulincer, 1998; Norris \& Zweigenhaft, 1999; Rempel, Ross, \& Holmes, 2001; Rousseau, Sitkin, Burt, \& Camerer, 1998; Simpson, 2007). Trust is among the most commonly cited cognitions associated with interpersonal sexual relations (Brady, Tschann, Ellen, \& Flores, 2009); in recent years, trust has become synonymous with fundamental aspects of attachment, pair-bonding, love, and the neurocognitive basis of monogamy (Carter, 2014).

Scientific definitions of trust vary depending on the context of use, although definitions typically include elements such as an expectancy that another individual can be relied upon (Rotter, 1967) and vulnerability based in a sense of safety created by those expectations (Evans \& Revelle, 2008). Dyadic trust—as distinguished from generalized trust—refers to the benevolence and honesty of a significant other toward the individual making the trust assessment (Larzelere \& Huston, 1980). The two preconditions of dyadic trust are mutual risk and interdependence (Rousseau et al., 1998). Dyadic trust is seen as an indicator of quality of romantic relationship functioning (Sullivan, Feinstein, Marshall, \& Mustanski, 2017).

"Trust," then, encompasses such a breadth of ingrained perspectives that its ubiquitous reference to interpersonal relationships frustrates precise definition of "sexual trust." The intrapersonal experiences of sexual trust and interpersonal expressions of trust become sexual in association with affiliations that include explicit sexual interaction. A full panoply of sexual interactions is of interest within this rubric. Dyads as well as connected networks (i.e., three or more concurrent persons) comprise the interpersonal basis for sexual interactions. Relationship structures, such as nonromantic, romantic, transactional, commercial, electronically mediated, and reproductive sex, are among categories to consider. Its complex forms link trust to relationship quality, emotional disclosure, intimacy, and love, as well as a cognitive assessment of a partner and a relationship (Evans \& Revelle, 2008; Fletcher, Simpson, \& Thomas, 2000; McCarthy, Wood, \& Holmes, 2017). Sexual trust may also act as a form of emotional regulation associated with risk avoidance and reward receptivity in interpersonal approach (Zak, Kurzban, \& Matzner, 2004). 
Other formations of trust also affect individual sexual health. For example, among women with low sexual desire, body trust is associated with lower concordance of subjective and physiological genital arousal (Velten \& Brotto, 2017). Body trust thus refers to a form of interoception translated into sexual response, rather than interpersonal generation of trust. Examples of microsocial sexual trust are drawn from studies of sexual decision making, where young adults describe formation of "paradigms of safety" in decisions about sexual relationships, and where "safe" sexual spaces emerge from associating ordinary locations and activities to signals of trust, privacy, comfort, and desire, generating contingent decisions about preventive behaviors (Hensel, Newcamp, Miles, \& Fortenberry, 2011; Mullinax et al., 2016b).

Macrosocial trust also influences sexual health outside of the individuals or sexual dyads, in that community-level influences reflective of trust, social cohesion, and collective efficacy influence sexual health-related outcomes, such as care seeking and condom use. For example, perceived neighborhood trust and cohesion is associated with lower perceived nonmonogamy for HIV-seropositive and HIVseronegative women living in the American South (Haley et al., 2018). Discussions of sexual identity of same-sex-attracted women and their physicians are related to both interpersonal reading of physicians as well as individual approaches to privacy management (McNair, Hegarty, \& Taft, 2012). Even general social constructs, such as institutional trust (defined as confidence in public authorities) and community trust (defined as confidence in individuals within one's neighborhood), are associated with condom use among 15- to 19-year-olds (Mmari, Marshall, Lantos, \& Blum, 2016). Translation of social-ecological trust into sexual health outcomes expands understanding of sexual trust beyond that associated with specific dyads and acts.

An important companion concept for sexual trust is sexual distrust. Sexual distrust is defined (as adapted from general definitions of distrust) as expectations of negative outcomes of sexual relationships and encounters, along with protective behavioral responses against these outcomes (Reimann, Schilke, \& Cook, 2017). Distrust or trust violations are frequently cited reasons for relationship dissolution 
(Connolly \& McIsaac, 2009; Watkins \& Boon, 2016). Distrust and trust may exist simultaneously within sexual relationships rather than a continuum where "distrust equals imperfect trust" (Kang \& Park, 2017).

Distinction of trust from distrust is more than theoretical: Trust and distrust activate different brain regions (Dimoka, 2010), and trust has a component of heritability but distrust does not (Cesarini et al., 2008; Reimann et al., 2017). Sexual and emotional health may be supported by distrust for a partner through disgust, vigilance, monitoring of vulnerabilities, and resistance to exploitation (Aarøe, Osmundsen, \& Petersen, 2016; Reimann et al., 2017). Both self-concealment and a partner's perceptions of self-concealment are associated with a reciprocal loss of trust and decline in relationship quality (Uysal, Lin, \& Bush, 2012). Women's distrust for a partner is associated with low relationship quality, and lack of effective HIV prevention interventions (Crankshaw, Voce, Butler, \& Darbes, 2016) and high levels of sex partner mistrust are often reported by HIV-positive persons (Higgins et al., 2014). Finally, sexual distrust is relevant because it violates cultural expectations of companionate monogamy, where distrust is a sign of anxious attachment and unstable bonding, (Rodriguez, DiBello, Øverup, \& Neighbors, 2015) and perhaps even of an imperfectly regulated society (Willig, 1997). Distrust increases the likelihood of condomless sex among victims of past violence, linking this sexual health outcome to other experiences of trust violation (Budhwani et al., 2017). Distrust in sexual relationships may be associated with depression and other mental health outcomes (Chen, Li, Li, \& Huang, 2017).

A second companion concept of sexual trust is sexual trustworthiness (Bird, Eversman, \& Voisin, 2017). Here, trustworthiness refers to assessment of social, physical, and contextual clues that support sexual trust (Ben-Ner \& Halldorsson, 2010). Trustworthiness plays an important role in formation of sexual relationships, potentially through overlap of neurocognitive networks (especially including parts of the amygdala) associated with attractiveness (Bzdok et al., 2011). Oxytocin and testosterone are both associated with assessments of general trustworthiness, although not in a linear or completely consistent fashion (Bos, Hermans, Ramsey, \& van Honk, 2012; Lambert, Declerck, \& Boone, 2014; Luo et al., 2017; Riedl, Javor, Gefen, Felten, \& Reuter, 2017; Zhong et al., 2012). Gender differences in assessments 
of trustworthiness are based on relative masculinity-femininity of faces, and masculinity-femininity of voice pitch (Sofer et al., 2017; Stirrat \& Perrett, 2010; Vukovic et al., 2011; Zhuang, Zhang, Xu, \& Hu, 2014). However, visual similarity, relationship context, and use of oral contraceptives may alter these relationships (DeBruine, 2005; Little et al., 2010; Puts, Jones, \& DeBruine, 2012; Smith et al., 2009; Vukovic et al., 2011; Zhuang et al., 2014). Assessments of trustworthiness are reduced in the preovulatory phase of the menstrual cycle (Ball et al., 2013), but the periovulatory phase is associated with increased ratings of attractiveness of masculine faces, even when information about trustworthiness is provided (Bzdok et al., 2011). Data on assessments of trustworthiness assessments between same-sex sexual dyads were not identified.

Finally, trust—at least dyadic trust—intersects with several other constructs associated with relationship quality: satisfaction, commitment, intimacy, passion, and love. In fact, data generated in development of one widely used scale of relationship quality — the Perceived Relationship Quality Components (PRQC) scale- showed correlations of $0.58,0.38,0.47,0.14$, and 0.48 for trust with satisfaction, commitment, intimacy, passion, and love, respectively (Fletcher et al., 2000). Items used to generate this trust subscale (e.g., "How much do you trust your partner? How much can you count on your partner? How dependable is your partner?") reflect dyadic trust rather than sexual trust. Sexual trust thus is situated within many key approach and bonding mechanisms used to organize sexual behaviors and interpret sexual experiences. Dyadic trust in some relationship configurations not based in monogamy (i.e., consensual nonmonogamies) also appears to relate to these diverse aspects of relationship quality (Balzarini et al., 2017; Barker \& Langdridge, 2010).

\section{Risk Regulation Models for Trust}

In risk regulation models, trust serves as relationship insurance by mitigating risk through accommodation and mutual dependence (Murray et al., 2009). The level of trust dyad members bring into the relationship, as well as the degree of risk to the relationship, work in a reinforcing cycle that supports 
overall relationship well-being, especially for those with high initial trust levels and low-risk partners (Murray, Holmes, Griffin, \& Derrick, 2015).

In romantic dyads, people high in trust respond to risk based on an appraisal of their partners and are motivated to make connections with approachable, accepting partners. Partner connection is achieved through cognitive and behavioral strategies that prioritize intimacy (Murray, Derrick, Leder, \& Holmes, 2008). In contrast, people low in trust resist their partners' benevolent intentions, responding to risk with self-protection (Cavallo, Murray, \& Holmes, 2014). Those with higher trust in partner responsiveness feel closer to partners on days following threat. These trust cognitions and behaviors prioritize connection over self-protection to support intimacy, but less trusting people prioritize self-protection after an acute relationship threat (Murray, Bellavia, Rose, \& Griffin, 2003). Between-person and between-situation variability in the balance of self-protection and connection also reflects balance in impulsive and reflective trust, mediated by working memory capacity (Murray et al., 2011). Developmental changes in working memory through adolescence (Romer et al., 2011), as well as situational variability in demands on working memory, explain variation in trust experiences at different times and in different relationships (Murray, Gomillion, Holmes, Harris, \& Lamarche, 2013; Murray, Lupien, \& Seery, 2012).

Trust interacts in important ways with self-esteem, so that even indirect risk exposure- among those low in trust - predicts attributions of blame and self-protection (MacKinnon \& Boon, 2012). High self-esteem and agreeableness are mediated by trust in association with emotional disclosure (McCarthy et al., 2017). Trust also closely reflects bonding and attachment (Mikulincer, 1998; Mikulincer \& Shaver, 2005) and attachment styles developed during infancy and childhood - initially focused on maternal figures but extended to family and then peers — are linked to the quality and outcomes of romantic/sexual interactions in middle and late adolescence (Furman, Stephenson, \& Rhoades, 2014; Letcher, 2013; Pascuzzo, Cyr, \& Moss, 2013; Szielasko, Symons, \& Price, 2013). Among adults, anxious attachment—associated with less trusting assessment in relational risk situations - is linked to between-person differences in approaches to self-protection in dyadic relationships. Although anxious attachment is associated with relatively low 
levels of relationship satisfaction and success, other key aspects of relationship context modify this expected association (Campbell \& Marshall, 2011; Stanton, Campbell, \& Pink, 2017). Attachment styles also influence sexual experiences, in that persons with higher attachment anxiety tend to react to sexual interactions with ambivalence, while those characterized by attachment avoidance react negatively, even with hostility (Birnbaum, Mikulincer, Szepsenwol, Shaver, \& Mizrahi, 2014; Birnbaum, Reis, Mikulincer, Gillath, \& Orpaz, 2006). Dyadic trust explains, at least in part, associations of attachment and couples' sexual goals (Impett, Gordon, \& Strachman, 2008), attachment styles and condom use (Starks, Castro, Castiblanco, \& Millar, 2017; Strachman \& Impett, 2009), and attachment styles and sexting behaviors (Trub \& Starks, 2017; Weisskirch, Drouin, \& Delevi, 2017).

\section{Role of Trust in Sexual Interactions}

The conceptualization of sexual trust used in this review differs from general dyadic trust in three ways. First, sex may create dyadic conflict, where commonplace motivations for sex (e.g., satiation of arousal, creation of intimacy and closeness, dominance and prestige; Meston \& Buss, 2007) conflict with motivations to avoid sexual rejection, stigma, and social exclusion (Murray et al., 2008). Moreover, motivations for sex may be interchangeable within a given dyad over the course of days, weeks, months, and years, with changes supported by trust and distrust experiences developing through repeated encounters, both sexual and nonsexual (Mullinax et al., 2016a). Specific sexual behaviors—-first coitus or first receptive anal sex, for example — are used to signal trust and serve as "gifts" to the partner, in part to maintain the dyad relationship (Carpenter, 2002; Norona, Welsh, Olmstead, \& Bliton, 2017).

Second, sex provides a significant opportunity for "diagnostic situations" in close relationships. Diagnostic situations are interpersonal events associated with risk (Rempel, Holmes, \& Zanna, 1985). Risk — emotional, physical, or social — is the activating condition for the responsive behaviors associated with trust (Cavallo et al., 2014; Rempel et al., 1985). For example, among the risks associated with sex, one might list the literal displays of nakedness, the disclosure of sexual secrets and preferences, body fluids that are stimuli for disgust and vehicles of disease, expectations for partner orgasm, and the stigma, 
condemnation, and corporal/capital punishment that may accompany social knowledge of sexual behavior.

Third, a concept of sexual trust supports a developmental sexual health perspective on partnered sexual relationships that emerges in early and middle adolescence and remains relevant for much of a person's remaining life span (Carpenter, 2010; Fortenberry, 2014). From adolescence into midadulthood, increasing age is associated with higher trust at the onset of social interactions, increased levels of trust during interactions with a trustworthy partner, and a stronger decline in trust during interactions with an unfair partner. This developmental shift toward higher trust may also be associated with an age-related increase in sensitivity to others' negative social signals (Derks, Lee, \& Krabbendam, 2014). Gender differences are notable for the importance of social context, in that cisgender birth-assigned males may have more rapid decline in trust in mistrust situations (Lemmers-Jansen, Krabbendam, Veltman, \& Fett, 2017).

\section{Sexual Trust and Sexual Health Outcomes}

This section of the review of sexual trust and sexual health was supported by searches of Ovid, Google Scholar, PsycINFO, and PubMed. Search terms included "sexual trust," "trust," "trustworthiness," and "distrust." The aim was an expansive, not necessarily exhaustive, survey of research literature. Individual papers were reviewed for use of words such as trust, distrust, trustworthiness, intimacy, commitment, and closeness. Information obtained from each paper included definitions and measurement of trust, definition and measurement of trustworthiness (if any), data collection method, sample description, and major result. Cited literature was also reviewed, as some relevant papers were not identified in the initial search strategy. Books and book chapters were not systematically included but used as sources for additional citations. All of the citations were in English.

Inclusion was initially considered of sexual experiences that violate emotional and physical autonomy, and therefore violate trust. However, the interplay of trauma, distrust, and the therapeutic ideal of 
rebuilding both dyadic and sexual trust seems so critical (and poorly theorized) as to require a different article with a different focus. The remainder of the review, then, contains three sections summarizing studies addressing sexual trust and sexual dyads; sexual trust and condomless sex (and other protective behaviors); and sexual trust in exchange-based sexual relationships.

\section{Sexual Trust and Sexual Dyads}

Although dyadic trust is often defined and measured as a traitlike quality (Rotter, 1967), the day-to-day trust experiences of a dyad member could vary significantly based on the level of threats and perceived risks relevant to that dyad. For example, among adolescent participants in a daily diary study, measures of trust, closeness, commitment, perceived risk of STI, perceived partner concurrency, and condom use all showed substantial day-to-day variation, with significant within-relationship variation (more than $40 \%$ of the variance) compared to between-relationship variance (Matson, Chung, Huettner, \& Ellen, 2014). In a longitudinal analysis, weeks with a decrease in partner trust were associated with a statistically significant 45\% increase in incident STI risk (Matson, Fortenberry, Chung, Gaydos, \& Ellen, 2018).

An observation across a number of qualitative papers is that trust is experienced as emotional safety rather than physical safety or protection from HIV/STI risk (Lanier, Stewart, Schensul, \& Guthrie, 2018). Knowing and trusting a partner influences beliefs about safety (Masaro, Dahinten, Johnson, Ogilvie, \& Patrick, 2008). Trust is a function of safe relationships, for example, "a person who you know and care for won't hurt you" (Baumann \& Berman, 2005). The "paradigms of safety" metaphor mentioned previously summarizes the ways trust is used, especially in early phases of formation of sexual relationships (Mullinax et al., 2016b). The interplay of trust and sexual desire is emphasized in formation of short-term sexual relationships with risk for STIs (Christianson, Johansson, Emmelin, \& Westman, 2003).

Sexual trust emphasizes the interplay of commitment, intimacy, and monogamy: Monogamous relationships are seen as inherently trusting and respectful (Towner, Dolcini, \& Harper, 2015). Many 
people define trust as a reflection of partner support and fidelity (Murray et al., 2013), reflecting monogamous intimacy (Khan, Hudson-Rodd, Saggers, Bhuiyan, \& Bhuiya, 2004). Intimacy is seen as protective against risk in the face of ongoing high-risk behaviors, even if there are inevitable "casualties" associated with dependence on trust as protection (Knox, Yi, Reddy, Maimane, \& Sandfort, 2010; Willig, 1997). Trust is therefore symbolic of the strength and nature of the romantic relationship and explicitly linked to fidelity and commitment. Monogamy as a relationship standard that reflects trust, intimacy, and safety — especially in terms of HIV risk - is seen in same-sex couples of both women and men (Duncan, Prestage, \& Grierson, 2015; Stevens \& Hall, 2001; Zak \& McDonald, 1997). Assessments of partner trustworthiness may be based in direct disclosures, as well as through comparison with experiences of trust betrayal in past relationships, indirect knowledge of a partner's extradyadic behaviors, a partner's reputation among peers, or even joint membership in one's larger community (Norona et al., 2017; Senior, Helmer, Chenhall, \& Burbank, 2014). Socially stigmatized relationships—for example, same-sex relationships or different-sex relationships of mixed race/ethnicity—are associated with lower relationship satisfaction, commitment, trust, love, and sexual communication, although this association is moderated by egalitarianism (Rosenthal \& Starks, 2015). Contexts such as perceptions of female power, or the degree to which trust is perceived to be uncalculated, are associated with greater trust and trustworthiness (Conroy et al., 2016; Jordan, Hoffman, Nowak, \& Rand, 2016; Lane \& Viney, 2002). Greater couplelevel differences in dyadic adjustment and commitment are associated with overestimation of a partner's viral suppression (Conroy et al., 2016).

Sexual trust has an important role in postsex interactions of the sexual dyad. Postsex interactionscuddling, for example - are associated with both relationship and sexual satisfaction in long-term, different sex dyads (Hughes \& Kruger, 2011) and are specifically related to the duration and quality of the postsex interactions (Muise, Giang, \& Impett, 2014). Postcoital cuddling has both nurturing and sexual qualities, potentially explaining testosterone elevations associated with these behaviors (van Anders, Edelstein, Wade, \& Samples-Steele, 2013). Postsex disclosure of positive feelings - in addition to the 
physical touches of cuddling - is associated with trust, relationship satisfaction, closeness, and orgasm (Denes, 2012). Trust as an element of partnered sexual pleasure is associated with sense of shared vulnerability and authentic expression of self (Goldey, Posh, Bell, \& van Anders, 2016).

Trust also operates in terms of sexual communications. Mutual trust and concern about creating questions about sexual risk are major influences on condom nonuse, sometimes based in indirect rather than direct communications (Campbell et al., 2014; Træen \& Gravningen, 2011). Direct safer-sex communication raises questions about past relationships and behaviors, which can reduce, rather than increase, trust (Lear, 1995). This loss of trust, however, has gendered meanings. For birth-assigned males, disclosures may simply signify past indiscretions, while for birth-assigned women, disclosures signify loss of trustworthiness as a low-risk partner (Gavin, 2000). Women report conditional trust of partners associated with strategic disclosure about microbicide use (Kelly et al., 2015). HIV serostatus disclosure involves three partner-specific issues: degree of sexual risk, partner type, and perceived partner trustworthiness (Bird et al., 2017). This is a point where trust may undermine sexual health-related disclosures: People in more trusting relationships take longer to disclose HIV infection status (Smith, Cook, \& Rohleder, 2017). In contexts such as bathhouses or "barebacking" parties, masculine ideologies, shared identities, and desire for intimacy are associated with disclosure of HIV infection status as well as discussion of condom use (Berg, 2009; Girard, 2016).

The apparently increasing prevalence of various forms of consensual nonmonogamy (Levine, Herbenick, Martinez, Fu, \& Dodge, 2018) reflects an important deficiency of research on dyadic trust and its associations with the involved sexual relationships. Consensual nonmonogamy reflects various relational configurations where partners mutually accept multiple sexual and romantic involvements (Barker \& Langdridge, 2010). Relationship configurations of consensual nonmonogamies differ in form and relational content: swinging (consensual involvement outside sexual partners without significant emotional attachments); polyamory (consensual sexual and romantic involvement, with varying degrees of primacy among relationships [Balzarini et al., 2017; Conley, Matsick, Moors, \& Ziegler, 2017], 
forming sexual networks of three or more people); and open relationships (a flexible option of extradyadic sex for members of an established dyad). Although trust and overall relationship quality are perceived as an important benefit of monogamy (Conley, Moors, Matsick, \& Ziegler, 2013), these may be equal to or actually higher among polyamorous relationships (Conley et al., 2017; Rubel \& Bogaert, 2015; Conley et al., 2017), although not among those reporting swinging or open relationship configurations (Conley et al., 2017).

\section{Sexual Trust and Social Network/Communication Technologies}

The formation of sexual trust in relationships associated with electronic media is not well defined. Generalized trust is associated with less use of online dating sites (Kang \& Hoffman, 2011) but is associated with intention to use dating apps (as opposed to dating sites, and although not for apps for finding sex partners) (Chan, 2017). Among some men who have sex with men, trust developed through online interactions is associated with unprotected sex (Fernández-Dávila \& Zaragoza Lorca, 2011). Display of sexual references on college freshmen's social media profiles is associated with intention to initiate sexual intercourse (Moreno, Brockman, Wasserheit, \& Christakis, 2012).

Social networking sites also allow monitoring of partners' relationships with others, where the association of relationship anxiety with jealousy was mediated by lower partner-specific trust (Marshall, Bejanyan, Di Castro, \& Lee, 2013). Adolescents use information from online postings to inform trust, understand partners through their past relationships, assess relationship status, and manage postbreakup relations (Van Ouytsel, Van Gool, Walrave, Ponnet, \& Peeters, 2016). Interpersonal trust is important in online relationships, but trust of the site itself is associated with perceived privacy of the site, moderated by the site's perceived security (Shin, 2010). It seems that social media sites themselves are incorporated into the overall environmental scan that signals sexual safety, expanding the paradigms of safety concept (Fernández-Dávila \& Zaragoza Lorca, 2011). 
Sexting reflects a particular adaptation of contemporary technology to sexual displays, arousal, and communication formerly requiring face-to-face interaction, and governed by older, now insufficient, standards for sexual privacy and confidentiality (Albury, 2017). Despite an unsettled understanding of the exact range of cell-phone mediated communications that constitute sexts, sexting is relatively common, although not ubiquitous (Klettke, Hallford, \& Mellor, 2014). For example, sexting prevalence in a national probability sample of students ages 12 to 18 was $17 \%$ for sending/receiving sexts and $24 \%$ for only receiving sexts (Rice et al., 2018). Sexting profiles are associated with between-person personality differences, including higher levels of anxious attachment (Trub \& Starks, 2017; Weisskirch \& Delevi, 2011; Weisskirch et al., 2017). Almost nothing is known about the degree to which sexts are associated with sexual aspects of subsequent encounters, or even if sexts are primarily sexual in intent. Sexual trustdistrust and revenge porn (and other forms of technology-based acts of sexual violence) have not been empirically assessed (Short, Brown, Pitchford, \& Barnes, 2017).

\section{Sexual Trust and Condomless Sex}

Infection prevention is an obvious public health representation of the balance of self-protection and intimate emotional and physical connection to others that may be resolved through sexual trust. Within the context of a high degree of effectiveness against most STIs, decisions for or against the use of a latex barrier - covering surfaces of the penis, vulva, vagina, and anus but preventing direct touch and fluid exchange - are interpreted as suppressors of trust, intimacy, and commitment (Appleby, Miller, \& Rothspan, 1999). In particular, trust — as an alternative to condoms - is viewed as an infection prevention practice based in ideals of committed monogamy. Trust contradicts both the need for protection and condoms' function as a barrier (Towner et al., 2015).

To provide additional structure for understanding trust and condomless sex, an excellent framework developed more than 20 years ago has been adopted (Willig, 1997). Sexual trust, from this perspective, is constructed from symbolic talk and actions rather than risk-informed cognitively assessed decisions.

Three categories of trust help deconstruct sexual trust in relationship to condomless sex: trust as security, 
trust as symbolic practice, and trust as social regulation. The sections that follow illustrate these categories through review of relevant research and emphasize key elements needed to understand sexual trust and condomless sex.

Trust as security is based in dyad members' confidence in trust that guarantees safety and makes condom use superfluous. Trust, monogamy, and closeness have intertwined meanings that define sexual relationships. Condomless sex is thus associated with multiple subjective assessments of partner safety, commitment to monogamy, and sexual pleasure (Civic, 2000). Trust is associated with assumptionsoften implicit rather than explicit—of monogamy (Duncan et al., 2015), linked with social values that condoms are for sex in casual but not committed relationships (Hattori, 2014; Zhang, Abler, Bao, \& Pan, 2014). Safety perceptions influence trust, intimacy, and commitment associated with a more formal relationship status defined by monogamy (Goldenberg, Finneran, Andes, \& Stephenson, 2015). The experience of trust is valued highly, is contradictory to the possibility of extradyadic sex, and is antithetical to ongoing condom use (Michael, 2003).

Trust as security has not been formally evaluated for effectiveness in infection prevention compared to condoms or other prevention approaches. Studies, largely of safety agreements in same-sex birth-assigned male couples, generally identify trust as a motivating factor in monogamous safety agreements, with dependability and faith subscales of trust associated with decreased likelihood of condomless sex (Darbes, Chakravarty, Neilands, Beougher, \& Hoff, 2014; Davidovich, de Wit, \& Stroebe, 2004; Gomez et al., 2012; Hoff \& Beougher, 2010; Hoff, Beougher, Chakravarty, Darbes, \& Neilands, 2010; Hoff, Chakravarty, Beougher, Neilands, \& Darbes, 2012; Mitchell, 2016; Mitchell, Champeau, \& Harvey, 2013; Mitchell, Harvey, Champeau, Moskowitz, \& Seal, 2012; Mitchell et al., 2016; Mitchell \& Petroll, 2013). However, other studies show that condomless extradyadic sex is not associated with faith, dependability, and predictability trust subscales but is inversely related to value on sexual agreement and modified by alcohol and drug use (Mitchell, 2016). 
Trust as symbolic practice is established by taking specific types of risks where the possibility of an unexpected outcome - for example, an STI — is a purposefully accepted sacrifice. Trust as symbolic practice operates by enhancing relationship quality rather than providing security (Brady et al., 2009), exemplified by this quote: "I can only sleep with someone I truly love, and using contraception is a proof that in your heart you do not trust the other person and he does not trust you" (Gammeltoft, 2002, p. 492). Condomless sex is a symbol of trust, hope, sensuality, love, intimacy, strategic gain, relationship stability, and coital frequency (Feldstein Ewing \& Bryan, 2015; Jones \& Oliver, 2007). Condom use is often present during early phases of a sexual relationship but discontinuation is an anticipated transition (Conley \& Rabinowitz, 2004), often based on nonverbal communication (Mullinax et al., 2016a). In fact, trust may be inferred from other sources of information, such as number of episodes of previous sex with a partner (Zablotska, Grulich, De Wit, \& Prestage, 2011). Symbolic privileging of sexual pleasure, particularly for men, is associated with condomless sex (Khan et al., 2004).

The symbolic practice aspect of trust can also be seen in inclusion of specific sexual behaviors within a dyad's sexual repertoire: Any given behavior is novel to a specific dyad at some point in time and may be a response either to achievement of a level of trust or to provide incentive toward such trust. Even discussion of desire for a potentially stigmatized behavior introduces relationship risk that may be resolved by trust (Kimberly, Williams, \& Creel, 2018). "First" experiences as "gifts" are often associated with loss of a cultural status of "virgin" (Arrington-Sanders, Rosenberger, Matson, Novak, \& Fortenberry, 2016; Carpenter, 2002; McBride \& Fortenberry, 2010; Walker, DeNardi, Messman-Moore, \& Rose, 2007). Dyadic trust is significantly associated with lower sexual risk but in the context of sensation seeking (Jones, 2004). In established dyads, demonstration of trust through healthy but relatively less frequently practiced behaviors (from a population perspective; bondage, discipline, dominance, and submission, for example) is an expression of the mutual trust of the partners in those dyads (Ernulf \& Innala, 1995; Faccio, Casini, \& Cipolletta, 2014; Graham, Butler, McGraw, Cannes, \& Smith, 2016; Richters, de Visser, Rissel, Grulich, \& Smith, 2008). Coitus interruptus as a contraceptive 
behavior may represent trust and negotiated safety and mark sexual prowess (Horner et al., 2009).

Symbolic emphasis of semen exchange is based in trust about intimacy and infection status, especially among same-sex birth-assigned male dyads (Mowlabocus, Harbottle, \& Witzel, 2014; Prestage, Hurley, \& Brown, 2013; Schilder et al., 2008).

Trust as social regulation positions dyadic trust as a defining element of a good society and therefore a requirement of socially acceptable relationships. Use of condoms implies not only lack of trust but reflects a society's vices (Zwane, Mngadi, \& Nxumalo, 2004). As one youth noted, "We did not use condoms because we are not married... . It would be very irrational to arrange for it, because we are not married so we cannot have sex regularly" (Gammeltoft, 2002, p. 493).

\section{Sexual Trust in Exchange-Based Sexual Events}

Historically and currently, many sexual interactions are conditioned on an explicit exchange of money, goods, or other services. These exchanges may be essential for survival and contribute to some or all of an individual's subsistence. These types of sexual events challenge the sexual trust models based in monogamy, often because of trauma histories that interfere with basic trust capacities, the relative lack of emotional engagement with partners, the stigma of exchange-based sex, the risks of physical violence by partners, and the relatively large number of partners for whom trust could be required. These issues certainly affect formation of sexual trust; however, sexual trust, as we shall see, still functions in recognizable ways in the lives of many who are broadly and vaguely characterized as "sex workers."

It is important to note that sex workers have different types of partners that include regular (noncommercial) romantic partners, one-time or infrequent returning exchange partners, and "regulars" who may establish some degree of intimacy based on repeated interactions (Robertson et al., 2014). Among sex workers with noncommercial romantic partners, communication is associated with trust and trust building. Trust is often invoked in explanation of love, along with respect, understanding, support, friendship, protection, and happiness, especially in terms of supportive responses to trauma, 
discrimination, and poverty. Factors associated with trust include depression, relationship satisfaction, relationship violence, and syringe sharing (Robertson et al., 2014; Syvertsen et al., 2015, 2013, 2013). Syringe sharing has emotional meanings of love and trust as well (Syvertsen et al., 2013).

Condomless sex with romantic partners is often a symbol of how sex workers prioritize the challenges of trust, intimacy, and sexual relationships with diverse partners. For example, condom use is relatively common with exchange partners, where STIs are common and health protection is important. With romantic partners, where condomless sex is more common, trust appears to follow the familiar patterns of trust as security and trust as symbolic practice. Here, sexual relationships follow a model based on love, trust, and emotional fidelity (Lazar, Sanclemente, Ferrer, Folch, \& Casabona, 2015).

Understanding of sexual trust in erotic film actors - in terms of on-screen partners, off-screen partners, and romantic partners - has some basis in popular culture literature and autobiographical stories of performers. Despite some literature to address issues of mental health and sexual well-being among performers (Griffith, Hayworth, Adams, Mitchell, \& Hart, 2013; Griffith, Mitchell, Hart, Adams, \& Gu, 2013), none address sexual and dyadic trust in ways comparable to that based on other categories of sex worker. Occupational safety regulations to require condom use in erotic films raises other questions about how sexual trust interacts with professional and nonprofessional condomless sex, lending practical significance to the topic (McKee, 2016).

\section{The Role of Trust in Sexual Health: Implications for Theory, Research, and Practice}

Trust enables sexual relationships and behaviors directly linked to both positive and negative outcomes. On the positive side, trust contributes to experiences of safety, intimacy, satisfaction, and pleasure that constitute overall sexual well-being and relationship stability (Harris, Bedard, Moen, \& Álvarez-Pérez, 2016; Laumann et al., 2006; Mullinax et al., 2016b). In fact, trust has a central symbolic role that is a standard for evaluation of relationship quality and stability across diverse relationship structures (Conley et al., 2017; van Hooff, 2017; Kemer, Bulgan, \& Y1ldı, 2016; Norona et al., 2017). 
On the negative side, trust and distrust are associated with jealousy and intimate partner violence (Rodriguez et al., 2015) as well as the STIs (including HIV) that are directly risked by condomless sex associated with sexual and relational trust (Ibañez et al., 2017). Expanding trust, recovering trust, and the experiences of trust violations are frequent themes of sexual and marital clinical therapy and counseling (Thompson \& O'Sullivan, 2016). Certainly, the central role of trust and trust violations in romantic relationships is a continuously represented element of modern literary and musical culture (Barclay, 2017).

The pervasive contradictions of sexual trust are heightened by the lack of an integrated theory that incorporates cognitive, behavioral, social, brain, and hormonal elements of trust (and companion constructs of distrust and trustworthiness) into a model capable of addressing the contradictions that trust brings to sexual health and well-being (van Anders, Goodson, \& Kingsbury, 2013). In absence of such a theory, but toward its future elaboration, three general observations can be made about sexual trust as reflected in this review.

\section{Perspectives on sexual trust are based on increasingly insufficient frameworks of} heteronormative monogamy and fidelity. Most theoretical and empirical trust research is constructed around (usually implicit) mono- and heteronormative frameworks. These frameworks provide insufficient understanding of the emotional safety and relationship-building functions of trust in other relationship structures. A new (or newer) theoretical approach would emphasize the function(s) of trust in diverse patterns of sexual relationships and the ways in which trust interacts with attachments, commitment, fidelity, sexual repertoire, disease prevention and fertility management, household arrangements, and child-rearing (Balzarini et al., 2017). Consideration of categories such as polyamory, swinging, and open relationships would be helpful, and extension to even more nuanced relationship arrays within such categories (e.g., polyamory), would enlighten understanding of the forms of trust in the diverse relational configurations there (Barker 
\& Langdridge, 2010). This does not diminish the importance of monogamy. It simply makes interrogative room for other normalities in space now dominated by mononormativity.

2. Sexual trust in relation to sexual health is operative in multiple interpersonal and social contexts. Here, we have begun to understand how experiences of neighborhood violence, for example, influence the formation and conduct of sexual relationships that require trust (Decker et al., 2016; Sullivan et al., 2017). We also see that the disruptions of trust and sexual relationships caused by incarcerations of sexual/gender minorities and people of color are systemic influences outside of the interpersonal relationships (Adimora et al., 2001; Brennan et al., 2012; Underhill, Dumont, \& Operario, 2014). Policing practices intended to ensure community safety are potentially damaging to sexual health through systematic perceptions of racial discrimination, sexual identity discrimination, and discrimination based on gender performance (Parker, Parker, Philbin, \& Hirsch, 2018). Theoretical frameworks of neighborhood and community influences on sexual behavior, such as minority stress, microaggressions, and structural stigma, all include elements of trust and distrust that could explain adverse influences on sexual health (Hatzenbuehler, 2017; Nadal, Davidoff, Davis, \& Wong, 2014; Platt \& Lenzen, 2013; Sullivan et al., 2017).

3. Trauma experiences and sex-positive trust. Many people experience such significant sexual trauma that sex itself is thereafter contaminated and distasteful. Trust is an especially challenging aspect of sexual relationships in light of the large proportion of people who have experienced sexual trauma (Bird, LaSala, Hidalgo, Kuhns, \& Garofalo, 2017; Haley et al., 2018; Sullivan et al., 2017). Perhaps it is time to reinvigorate "sex positivity" as a framework for addressing sexual health. Addressing trust through a sex positivity lens emphasizes the diverse functions of trust in the cognitive, emotional, and physical experiences of sex. Such a perspective could incorporate a broad understanding of trust rather than depend on assumptions of trust as a dangerously unreliable means of informed sexual decision making. From a public health perspective, this means that same-sex relationships, noncisgender relationships, and exchange sex relationships, 
for example, cannot be effectively addressed on a basis of epidemiologic risk (Barr, Budge, \& Adelson, 2016; Hart et al., 2016; Rohleder, McDermott, \& Cook, 2017). Practical adaptation of sex positivity requires new public health approaches that recognize the linkages of trauma experiences to adverse sexual health outcomes and provide a therapeutic response in support of long-term sexual health (Decker et al., 2016; London, Quinn, Scheidell, Frueh, \& Khan, 2017; Sullivan et al., 2017).

This review began with the interrogation of the quotidian expression of trust in sexual relationships, where such expressions often lead to outcomes that contradict the initial trust. That particularly myopic view made it difficult to see the places where trust affirms the content of a relationship. Trust has many expressions in our sexuality and sexual behaviors, although it seems unlikely—based on the broad influences of trust in our lives - to contain an element that can be delimited as strictly "sexual." However, continued elaboration of how trust functions and contributes to sexual health has many possibilities over the next few years. 


\section{References}

Aarøe, L., Osmundsen, M., \& Petersen, M. B. (2016). 'Distrust as a disease avoidance strategy: Individual differences in disgust sensitivity regulate generalized social trust': Corrigendum. Frontiers in Psychology, 7, 1038. doi:10.3389/fpsyg.2016.01038

Adimora, A. A., Schoenbach, V. J., Martinson, F. E., Donaldson, K. H., Fullilove, R. E., \& Aral, S. O. (2001). Social context of sexual relationships among rural African Americans. Sexually Transmitted Diseases, 28, 69-76.

Albury, K. (2017). Just because it's public doesn't mean it's any of your business: Adults' and children's sexual rights in digitally mediated spaces. New Media \& Society, 19, 713-725. doi: $10.1177 / 1461444816686322$

Amy, -J.-J., \& Thiery, M. (2015). The condom: A turbulent history. The European Journal of Contraception \& Reproductive Health Care, 20, 387-402. doi:10.3109/13625187.2015.1050716

Appleby, P. R., Miller, L. C., \& Rothspan, S. (1999). The paradox of trust for male couples: When risking is a part of loving. Personal Relationships, 6, 81-93. doi:10.1111/j.1475-

6811.1999.tb00212.x

Arrington-Sanders, R., Rosenberger, J. G., Matson, P., Novak, D. S., \& Fortenberry, J. D. (2016). Factors associated with emotional satisfaction during first anal intercourse in a sample of YMSM. Journal of Homosexuality, 63, 968-984. doi:10.1080/00918369.2015.1113836

Ball, A., Wolf, C. C., Ocklenburg, S., Herrmann, B. L., Pinnow, M., Brüne, M., ... Güntürkün, O. (2013). Variability in ratings of trustworthiness across the menstrual cycle. Biological Psychology, 93, 52-57. doi:10.1016/j.biopsycho.2013.01.005 
Balzarini, R. N., Campbell, L., Kohut, T., Holmes, B. M., Lehmiller, J. J., Harman, J. J., \& Atkins, N. (2017). Perceptions of primary and secondary relationships in polyamory. PLOS ONE, 12. doi:10.1371/journal.pone.0177841

Balzarini, R. N., Shumlich, E. J., Kohut, T., \& Campbell, L. (2018). Dimming the "halo" around monogamy: Re-assessing stigma surrounding consensually non-monogamous romantic relationships as a function of personal relationship orientation. Frontiers in Psychology, 9(894). doi:10.3389/fpsyg.2018.00894

Barclay, K. (2017). Love and violence in the music of late modernity. Popular Music and Society, 117. doi:10.1080/03007766.2017.1378526

Barker, M., \& Langdridge, D. (2010). Whatever happened to non-monogamies? Critical reflections on recent research and theory. Sexualities, 13, 748-772. doi:10.1177/1363460710384645

Barr, S. M., Budge, S. L., \& Adelson, J. L. (2016). Transgender community belongingness as a mediator between strength of transgender identity and well-being. Journal of Counseling Psychology, 63, 87-97. doi:10.1037/cou0000127

Baumann, L. J., \& Berman, R. (2005). Adolescent relationships and condom use: Trust, love and commitment. AIDS \& Behavior, 9, 211-222. doi:10.1007/s10461-005-3902-2

Ben-Ner, A., \& Halldorsson, F. (2010). Trusting and trustworthiness: What are they, how to measure them, and what affects them. Journal of Economic Psychology, 31, 64-79.

doi:10.1016/j.joep.2009.10.001

Berg, R. C. (2009). Barebacking: A review of the literature. Archives of Sexual Behavior, 38, 754764. doi:10.1007/s10508-008-9462-6 
Bird, J. D., LaSala, M. C., Hidalgo, M. A., Kuhns, L. M., \& Garofalo, R. (2017). "I had to go to the streets to get love": Pathways from parental rejection to HIV risk among young gay and bisexual men. Journal of Homosexuality, 64, 321-342. doi:10.1080/00918369.2016.1179039

Bird, J. D. P., Eversman, M., \& Voisin, D. R. (2017). 'You just can't trust everybody': The impact of sexual risk, partner type and perceived partner trustworthiness on HIV-status disclosure decisions among HIV-positive black gay and bisexual men. Culture, Health \& Sexuality, 19, 829-843. doi:10.1080/13691058.2016.1267408

Birnbaum, G. E., Mikulincer, M., Szepsenwol, O., Shaver, P. R., \& Mizrahi, M. (2014). When sex goes wrong: A behavioral systems perspective on individual differences in sexual attitudes, motives, feelings, and behaviors. Journal of Personality and Social Psychology, 106, 822-842.

doi:10.1037/a0036021

Birnbaum, G. E., Reis, H. T., Mikulincer, M., Gillath, O., \& Orpaz, A. (2006). When sex is more than just sex: Attachment orientations, sexual experience, and relationship quality. Journal of Personality and Social Psychology, 91, 929-943. doi:10.1037/a0036021

Bos, P. A., Hermans, E. J., Ramsey, N. F., \& van Honk, J. (2012). The neural mechanisms by which testosterone acts on interpersonal trust. Neuroimage, 61, 730-737. doi:10.1016/j.neuroimage.2012.04.002

Brady, S. S., Tschann, J. M., Ellen, J. M., \& Flores, E. (2009). Infidelity, trust, and condom use among Latino youth in dating relationships. Sexually Transmitted Diseases, 36, 227-231. doi:10.1097/OLQ.0b013e3181901cba

Brennan, J., Kuhns, L. M., Johnson, A. K., Belzer, M., Wilson, E. C., \& Garofalo, R.; Adolescent Medicine Trials Network for HIV/AIDS. (2012). Syndemic theory and HIV-related risk among young transgender women: The role of multiple, co-occurring health problems and social marginalization. American Journal of Public Health, 102, 1751-1757. doi:10.2105/AJPH.2011.300433 
Budhwani, H., Turan, B., Hasbun, J., Rosario, S., Tillotson, L., McGlaughlin, E., \& Waters, J. (2017). Association between violence exposure and condom non-use among transgender sex workers in the Dominican Republic: The mediating role of trust. International Journal of STD \& AIDS, 28, 608612. doi:10.1177/0956462416659421

Butler, J. K. (1986). Reciprocity of dyadic trust in close male-female relationships. The Journal of Social Psychology, 126, 579-591. doi:10.1080/00224545.1986.9713630

Bzdok, D., Langner, R., Caspers, S., Kurth, F., Habel, U., Zilles, K., ... Eickhoff, S. B. (2011). ALE meta-analysis on facial judgments of trustworthiness and attractiveness. Brain Structure \& Function, 215, 209-223. doi:10.1007/s00429-010-0287-4

Campbell, C. K., Gomez, A. M., Dworkin, S., Wilson, P. A., Grisham, K. K., McReynolds, J., ... Hoff, C. (2014). Health, trust, or "just understood": Explicit and implicit condom decision-making processes among black, white, and interracial same-sex male couples. Archives of Sexual Behavior, 43, 697-706. doi:10.1007/s10508-013-0146-5

Campbell, L., \& Marshall, T. (2011). Anxious attachment and relationship processes: An interactionist perspective. Journal of Personality, 79, 917-947. doi:10.1111/j.14676494.2011.00723.x

Carpenter, L. M. (2002). Gender and the meaning and experience of virginity loss in the contemporary United States. Gender and Society, 16, 345-365. doi:10.1177/0891243202016003005

Carpenter, L. M. (2010). Gendered sexuality over the life course: A conceptual framework. Sociological Perspectives, 53, 155-178. doi:10.1525/sop.2010.53.2.155

Carter, C. S. (2014). Oxytocin pathways and the evolution of human behavior. Annual Review of Psychology, 65, 17-39. doi:10.1146/annurev-psych-010213-115110 
Cavallo, J. V., Murray, S. L., \& Holmes, J. G. (2014). Risk regulation in close relationships. In M. Mikulincer, P. R. Shaver, M. Mikulincer, \& P. R. Shaver (Eds.), Mechanisms of social connection: From brain to group (pp. 237-254). Washington, DC, US: American Psychological Association.

Cesarini, D., Dawes, C. T., Fowler, J. H., Johannesson, M., Lichtenstein, P., \& Wallace, B. (2008). Heritability of cooperative behavior in the trust game. Proceedings of the National Academy of Sciences, 105, 3721-3726. doi:10.1073/pnas.0710069105

Chan, L. S. (2017). Who uses dating apps? Exploring the relationships among trust, sensationseeking, smartphone use, and the intent to use dating apps based on the integrative model. Computers in Human Behavior, 72, 246-258. doi:10.1016/j.chb.2017.02.053

Chen, H., Li, X., Li, B., \& Huang, A. (2017). Negative trust and depression among female sex workers in Western China: The mediating role of thwarted belongingness. Psychiatry Research, 256, 448-452. doi:10.1016/j.psychres.2017.06.031

Christianson, M., Johansson, E., Emmelin, M., \& Westman, G. (2003). “One-night stands” — Risky trips between lust and trust: Qualitative interviews with Chlamydia trachomatis infected youth in north Sweden. Scandinavian Journal of Public Health, 31, 44-50. doi:10.1080/14034940210134158

Christopher, F. S., \& Cate, R. M. (1988). Premarital sexual involvement: A developmental investigation of relational correlates. Adolescence, 23, 793-803.

Civic, D. (1999). The association between characteristics of dating relationships and condom use among heterosexual young adults. AIDS Education \& Prevention, 11, 343-352.

Civic, D. (2000). College students' reasons for nonuse of condoms within dating relationships. Journal of Sex \& Marital Therapy, 26, 95-105. doi:10.1080/009262300278678 
Conley, T. D., Matsick, J. L., Moors, A. C., \& Ziegler, A. (2017). Investigation of consensually nonmonogamous relationships: Theories, methods, and new directions. Perspectives on Psychological Science, 12, 205-232. doi:10.1177/1745691616667925

Conley, T. D., Matsick, J. L., Moors, A. C., Ziegler, A., \& Rubin, J. D. (2015). Re-examining the effectiveness of monogamy as an STI-preventive strategy. Preventive Medicine: An International Journal Devoted to Practice and Theory, 78, 23-28. doi:10.1016/j.ypmed.2015.06.006

Conley, T. D., Moors, A. C., Matsick, J. L., \& Ziegler, A. (2013). The fewer the merrier? Assessing stigma surrounding consensually non-monogamous romantic relationships. Analyses of Social Issues and Public Policy, 13, 1-30. doi:10.1111/j.1530-2415.2012.01286.x

Conley, T. D., \& Rabinowitz, J. L. (2004). Scripts, close relationships, and symbolic meanings of contraceptives. Personal Relationships, 11, 539-558. doi:10.1111/j.1475-6811.2004.00097.x

Connolly, J., \& McIsaac, C. (2009). Adolescents' explanations for romantic dissolutions: A developmental perspective. Journal of Adolescence, 32, 1209-1223.

doi:10.1016/j.adolescence.2009.01.006

Conroy, A. A., Gamarel, K. E., Neilands, T. B., Dilworth, S. E., Darbes, L. A., \& Johnson, M. O. (2016). Relationship dynamics and partner beliefs about viral suppression: A longitudinal study of male couples living with HIV/AIDS (The Duo Project). AIDS \& Behavior, 20, 1572-1583. doi:10.1007/s10461-016-1423-9

Costa, F. M., Jessor, R., Donovan, J. E., \& Fortenberry, J. D. (1995). Early initiation of sexual intercourse: The influence of psychosocial unconventionality. Journal of Research on Adolescence, 5, 93-121. doi:10.1207/jra.1995.5.issue-1 
Costa, F. M., Jessor, R., Fortenberry, J. D., \& Donovan, J. E. (1996). Psychosocial conventionality, health orientation, and contraceptive use in adolescence. Journal of Adolescent Health, 18, 404-416. doi:10.1016/1054-139X(95)00192-U

Crankshaw, T. L., Voce, A., Butler, L. M., \& Darbes, L. (2016). Expanding the relationship context for couple-based HIV prevention: Elucidating women's perspectives on non-traditional sexual partnerships. Social Science \& Medicine, 166, 169-176. doi:10.1016/j.socscimed.2016.08.020

Darbes, L. A., Chakravarty, D., Neilands, T. B., Beougher, S. C., \& Hoff, C. C. (2014). Sexual risk for HIV among gay male couples: A longitudinal study of the impact of relationship dynamics. Archives of Sexual Behavior, 43, 47-60. doi:10.1007/s10508-013-0206-x

Davidovich, U., de Wit, J. B., \& Stroebe, W. (2004). Behavioral and cognitive barriers to safer sex between men in steady relationships: Implications for prevention strategies. AIDS Education \& Prevention, 16, 304-314. doi:10.1521/aeap.16.4.304.40398

DeBruine, L. M. (2005). Trustworthy but not lust-worthy: Context-specific effects of facial resemblance. Proceedings of the Royal Society of London - Series B: Biological Sciences, 272(1566), 919-922. doi:10.1098/rspb.2004.3003

Decker, M. R., Benning, L., Weber, K. M., Sherman, S. G., Adedimeji, A., Wilson, T. E., ... Golub, E. T. (2016). Physical and sexual violence predictors: 20 years of the women's interagency HIV study cohort. American Journal of Preventive Medicine, 51, 731-742. doi:10.1016/j.amepre.2016.07.005

Denes, A. (2012). Pillow talk: Exploring disclosures after sexual activity. Western Journal of Communication, 76, 91-108. doi:10.1080/10570314.2011.651253

Derks, J., Lee, N. C., \& Krabbendam, L. (2014). Adolescent trust and trustworthiness: Role of gender and social value orientation. Journal of Adolescence, 37, 1379-1386.

doi:10.1016/j.adolescence.2014.09.014 
Dimoka, A. (2010). What does the brain tell us about trust and distrust? Evidence from a functional neuroimaging study. MIS Quarterly, 34, 373-396. doi:10.2307/20721433

Duncan, D., Prestage, G., \& Grierson, J. (2015). Trust, commitment, love and sex: HIV, monogamy, and gay men. Journal of Sex \& Marital Therapy, 41, 345-360. doi:10.1080/0092623X.2014.915902

Ernulf, K. E., \& Innala, S. M. (1995). Sexual bondage: A review and unobtrusive investigation. Archives of Sexual Behavior, 24, 631-654. doi:10.1007/BF01542185

Evans, A. M., \& Revelle, W. (2008). Survey and behavioral measurements of interpersonal trust. Journal of Research in Personality, 42, 1585-1593. doi:10.1016/j.jrp.2008.07.011

Faccio, E., Casini, C., \& Cipolletta, S. (2014). Forbidden games: The construction of sexuality and sexual pleasure by BDSM 'players'. Culture, Health \& Sexuality, 16, 752-764.

doi:10.1080/13691058.2014.909531

Feldstein Ewing, S. W., \& Bryan, A. D. (2015). A question of love and trust? The role of relationship factors in adolescent sexual decision making. Journal of Developmental and Behavioral Pediatrics, 36, 628-634. doi:10.1097/DBP.0000000000000190

Fernández-Dávila, P., \& Zaragoza Lorca, K. (2011). Trust and sexual interaction: The significance of the internet on the sex life and sexual risk behaviors of gay and bisexual men in Spain. International Journal of Sexual Health, 23, 120-138. doi:10.1080/19317611.2011.566307

Fletcher, G. J. O., Simpson, J. A., \& Thomas, G. (2000). The measurement of perceived relationship quality components: A confirmatory factor analytic approach. Personality and Social Psychology Bulletin, 263, 340-354. doi:10.1177/0146167200265007

Fortenberry, J. D. (2014). Sexual learning, sexual experience, and healthy adolescent sex. New Directions for Child and Adolescent Development, 2014(144), 71-86. doi:10.1002/cad.20061 
Fortenberry, J. D., Tu, W., Harezlak, J., Katz, B. P., \& Orr, D. P. (2002). Condom use as a function of time in new and established adolescent sexual relationships. American Journal of Public Health, 92, 211-213.

Furman, W., Stephenson, J. C., \& Rhoades, G. K. (2014). Positive interactions and avoidant and anxious representations in relationships with parents, friends, and romantic partners. Journal of Research on Adolescence, 24, 615-629. doi:10.1111/jora.12052

Gammeltoft, T. (2002). Seeking trust and transcendence: Sexual risk-taking among Vietnamese youth. Social Science \& Medicine, 55, 483-496. doi:10.1016/S0277-9536(01)00182-4

Gavin, J. (2000). Arousing suspicion and violating trust: The lived ideology of safe sex talk. Culture, Health \& Sexuality, 2, 117-134. doi:10.1080/136910500300750

Girard, G. (2016). HIV risk and sense of community: French gay male discourses on barebacking. Culture, Health \& Sexuality, 18, 15-29. doi:10.1080/13691058.2015.1063813

Goldenberg, T., Finneran, C., Andes, K. L., \& Stephenson, R. (2015). 'Sometimes people let love conquer them': How love, intimacy, and trust in relationships between men who have sex with men influence perceptions of sexual risk and sexual decision-making. Culture, Health \& Sexuality, 17, 607-622. doi:10.1080/13691058.2014.979884

Goldey, K. L., Posh, A. R., Bell, S. N., \& van Anders, S. M. (2016). Defining pleasure: A focus group study of solitary and partnered sexual pleasure in queer and heterosexual women. Archives of Sexual Behavior, 45, 2137-2154. doi:10.1007/s10508-016-0704-8

Gomez, A. M., Beougher, S. C., Chakravarty, D., Neilands, T. B., Mandic, C. G., Darbes, L. A., \& Hoff, C. C. (2012). Relationship dynamics as predictors of broken agreements about outside sexual partners: Implications for HIV prevention among gay couples. AIDS \& Behavior, 16, 1584-1588. doi:10.1007/s10461-011-0074-0 
Gostin, L. O. (2013). PEPFAR's antiprostitution pedge: Spending power and free speech in tension. JAMA: Journal of the American Medical Association, 310, 1127-1128.

doi:10.1001/jama.2013.276527

Graham, B. C., Butler, S. E., McGraw, R., Cannes, S. M., \& Smith, J. (2016). Member perspectives on the role of BDSM communities. Journal of Sex Research, 53, 895-909. doi:10.1080/00224499.2015.1067758

Griffith, J. D., Hayworth, M., Adams, L. T., Mitchell, S., \& Hart, C. (2013). Characteristics of pornography film actors: Self-report versus perceptions of college students. Archives of Sexual Behavior, 42, 637-647. doi:10.1007/s10508-012-0033-5

Griffith, J. D., Mitchell, S., Hart, C. L., Adams, L. T., \& Gu, L. L. (2013). Pornography actresses: An assessment of the damaged goods hypothesis. Journal of Sex Research, 50, 621-632. doi:10.1080/00224499.2012.719168

Haley, D. F., Wingood, G. M., Kramer, M. R., Haardörfer, R., Adimora, A. A., Rubtsova, A., ... Cooper, H. L. F. (2018). Associations between neighborhood characteristics, social cohesion, and perceived sex partner risk and non-monogamy among HIV-seropositive and HIV-seronegative women in the Southern U.S. Archives of Sexual Behavior, 47, 1451-1463. doi:10.1007/s10508-018$1205-8$

Harris, V. W., Bedard, K., Moen, D., \& Álvarez-Pérez, P. (2016). The role of friendship, trust, and love in happy German marriages. Marriage \& Family Review, 52, 262-304.

doi:10.1080/01494929.2015.1095268

Hart, T. A., Willis, A. C., Simpson, S. H., Julien, R. E., Hoe, D., Leahy, B., ... Adam, B. D. (2016). Gay poz sex: A sexual health promotion intervention for HIV-positive gay and bisexual men. Cognitive and Behavioral Practice, 23, 517-529. doi:10.1016/j.cbpra.2015.11.002 
Hattori, M. K. (2014). Trust and condom use among young adults in relationships in Dar es Salaam, Tanzania. Journal of Biosocial Science, 46, 651-668. doi:10.1017/S0021932013000680

Hatzenbuehler, M. L. (2017). Advancing research on structural stigma and sexual orientation disparities in mental health among youth. Journal of Clinical Child and Adolescent Psychology, 46, 463-475. doi:10.1080/15374416.2016.1247360

He, F., Hensel, D. J., Harezlak, J., \& Fortenberry, J. D. (2016). Condom use as a function of number of coital events in new relationships. Sexually Transmitted Diseases, 43, 67-70. doi:10.1097/OLQ.0000000000000390

Hein, K. (1992). Adolescents at risk for HIV infection. In R. J. DiClemente (Ed.), Adolescents and AIDS: A Generation in Jeopardy (pp. 3-16). Newbury Park, CA: Sage Publications.

Hensel, D. J., Newcamp, J., Miles, J., \& Fortenberry, J. D. (2011). Picturing sexual spaces in everyday life: Exploring the construction of sexuality and sexual behavior among early adult women. Sexuality Research \& Social Policy: A Journal of the NSRC, 8, 267-281. doi:10.1007/s13178-0110066-x

Higgins, J. A., Mathur, S., Eckel, E., Kelley, L., Nakyanjo, N., Sekamwa, R., ... Santelli, J. S. (2014). Importance of relationship context in HIV transmission: Results from a qualitative case-control study in Rakai, Uganda. American Journal of Public Health, 104, 612-620.

doi:10.2105/AJPH.2013.301670

Hoff, C. C., \& Beougher, S. C. (2010). Sexual agreements among gay male couples. Archives of Sexual Behavior, 39, 774-787. doi:10.1007/s10508-008-9393-2

Hoff, C. C., Beougher, S. C., Chakravarty, D., Darbes, L. A., \& Neilands, T. B. (2010). Relationship characteristics and motivations behind agreements among gay male couples: Differences by agreement type and couple serostatus. AIDS Care, 22, 827-835. doi:10.1080/09540120903443384 
Hoff, C. C., Chakravarty, D., Beougher, S. C., Neilands, T. B., \& Darbes, L. A. (2012). Relationship characteristics associated with sexual risk behavior among MSM in committed relationships. AIDS Patient Care \& STDS, 26, 738-745. doi:10.1089/apc.2012.0198

Horner, J. R., Salazar, L. F., Romer, D., Vanable, P. A., DiClemente, R., Carey, M. P., ... Brown, L. K. (2009). Withdrawal (coitus interruptus) as a sexual risk reduction strategy: Perspectives from African-American adolescents. Archives of Sexual Behavior, 38, 779-787. doi:10.1007/s10508-0079304-y

Hughes, S. M., \& Kruger, D. J. (2011). Sex differences in post-coital behaviors in long- and shortterm mating: An evolutionary perspective. Journal of Sex Research, 48, 496-505. doi:10.1080/00224499.2010.501915

Ibañez, G. E., Whitt, E., Avent, T., Martin, S. S., Varga, L. M., Cano, M. A., \& O’Connell, D. J. (2017). 'Love and trust, you can be blinded': HIV risk within relationships among Latina women in Miami, Florida. Ethnicity \& Health, 22, 510-527. doi:10.1080/13557858.2016.1244737

Impett, E. A., Gordon, A. M., \& Strachman, A. (2008). Attachment and daily sexual goals: A study of dating couples. Personal Relationships, 15, 375-390. doi:10.1111/j.1475-6811.2008.00204.x

Jessor, R., \& Jessor, S. L. (1977). Problem behavior and psychosocial development: A longitudinal study of youth. New York, NY: Academic Press.

Jones, R. (2004). Relationships of sexual imposition, dyadic trust, and sensation seeking with sexual risk behavior in young Urban women. Research in Nursing \& Health, 27, 185-197.

doi:10.1002/nur.20016

Jones, R., \& Oliver, M. (2007). Young urban women's patterns of unprotected sex with men engaging in HIV risk behaviors. AIDS \& Behavior, 11, 812-821. doi:10.1007/s10461-006-9194-3 
Jordan, J. J., Hoffman, M., Nowak, M. A., \& Rand, D. G. (2016). Uncalculating cooperation is used to signal trustworthiness. Proceedings of the National Academy of Sciences of the United States of America, 113, 8658-8663. doi:10.1073/pnas.1601280113

Kang, M., \& Park, Y. E. (2017). Exploring trust and distrust as conceptually and empirically distinct constructs: Association with symmetrical communication and public engagement across four pairings of trust and distrust. Journal of Public Relations Research, 29, 114-135.

doi:10.1080/1062726X.2017.1337579

Kang, T., \& Hoffman, L. H. (2011). Why would you decide to use an online dating site? Factors that lead to online dating. Communication Research Reports, 28, 205-213.

doi:10.1080/08824096.2011.566109

Kelly, C. A., Friedland, B. A., Morar, N. S., Katzen, L. L., Ramjee, G., Mokgatle, M. M., \& Ahmed, K. (2015). To tell or not to tell: Male partner engagement in a Phase 3 microbicide efficacy trial in South Africa. Culture, Health \& Sexuality, 17, 1004-1020. doi:10.1080/13691058.2015.1030451

Kelly, J. A., \& Kalichman, S. C. (1995). Increased attention to human sexuality can improve HIVAIDS prevention efforts: Key research issues and directions. Journal of Consulting and Clinical Psychology, 63, 907-918. doi:10.1037/0022-006X.63.6.907

Kemer, G., Bulgan, G., \& Yıldız, E. Ç. (2016). Gender differences, infidelity, dyadic trust, and jealousy among married Turkish individuals. Current Psychology: A Journal for Diverse Perspectives on Diverse Psychological Issues, 35, 335-343. doi:10.1007/s12144-014-9298-2

Khan, S. I., Hudson-Rodd, N., Saggers, S., Bhuiyan, M. I., \& Bhuiya, A. (2004). Safer sex or pleasurable sex? Rethinking condom use in the AIDS era. Sexual Health, 1, 217-225. 
Kimberly, C., Williams, A. L., \& Creel, S. (2018). Women's introduction to alternative sexual behaviors through erotica and its association with sexual and relationship satisfaction. Sex Roles, 78, 119-129. doi:10.1007/s11199-017-0771-x

Klettke, B., Hallford, D. J., \& Mellor, D. J. (2014). Sexting prevalence and correlates: A systematic literature review. Clinical Psychology Review, 34, 44-53. doi:10.1016/j.cpr.2013.10.007

Knox, J., Yi, H., Reddy, V., Maimane, S., \& Sandfort, T. (2010). The fallacy of intimacy: Sexual risk behaviour and beliefs about trust and condom use among men who have sex with men in South Africa. Psychology, Health \& Medicine, 15, 660-671. doi:10.1080/13548506.2010.507772

Lambert, B., Declerck, C. H., \& Boone, C. (2014). Oxytocin does not make a face appear more trustworthy but improves the accuracy of trustworthiness judgments. Psychoneuroendocrinology, 40, 60-68. doi:10.1016/j.psyneuen.2013.10.015

Lane, L. G., \& Viney, L. L. L. (2002). Toward better prevention: Constructions of trust in the sexual relationships of young women. Journal of Applied Social Psychology, 32, 700-718. doi:10.1111/j.1559-1816.2002.tb00238.x

Lanier, Y., Stewart, J. M., Schensul, J. J., \& Guthrie, B. J. (2018). Moving beyond age: An exploratory qualitative study on the context of young African American men and women's sexual debut. Journal of Racial and Ethnic Health Disparities, 5, 261-270. doi:10.1007/s40615-017-0366-9

Larzelere, R. E., \& Huston, T. L. (1980). The Dyadic Trust Scale: Toward understanding interpersonal trust in close relationships. Journal of Marriage and the Family, 42, 595-604. doi:10.2307/351903

Laumann, E. O., Paik, A., Glasser, D. B., Kang, J.-H., Wang, T., Levinson, B., ... Gingell, C. (2006). A cross- national study of subjective sexual well-being among older women and men: Findings from 
the Global Study of Sexual Attitudes and Behaviors. Archives of Sexual Behavior, 35, 143-159. doi:10.1007/s10508-005-9005-3

Lazar, C., Sanclemente, C., Ferrer, L., Folch, C., \& Casabona, J. (2015). Condom use among female sex workers in Catalonia: Why do they use a condom, why don't they use it? AIDS Education and Prevention, 27, 180-193. doi:10.1521/aeap.2015.27.2.180

Lear, D. (1995). Sexual communication in the age of AIDS: The construction of risk and trust among young adults. Social Science \& Medicine, 41, 1311-1323. doi:10.1016/0277-9536(95)00010-5

Lemmers-Jansen, I. L. J., Krabbendam, L., Veltman, D. J., \& Fett, A.-K. J. (2017). Boys vs. girls: Gender differences in the neural development of trust and reciprocity depend on social context. Developmental Cognitive Neuroscience, 25, 235-245. doi:10.1016/j.den.2017.02.001

Letcher, A. (2013). Substance use, sexual activity, and attachment in adolescent romantic couples. Journal of Applied Social Psychology, 43, 1459-1467. doi:10.1111/jasp.12102

Levine, E. C., Herbenick, D., Martinez, O., Fu, T.-C., \& Dodge, B. (2018). Open relationships, nonconsensual nonmonogamy, and monogamy among U.S. adults: Findings from the 2012 National Survey of Sexual Health and Behavior. Archives of Sexual Behavior, 47, 1439-1450. doi:10.1007/s10508-018-1178-7

Little, A. C., Saxton, T. K., Roberts, S. C., Jones, B. C., Debruine, L. M., Vukovic, J., ... Chenore, T. (2010). Women's preferences for masculinity in male faces are highest during reproductive age range and lower around puberty and post-menopause. Psychoneuroendocrinology, 35, 912-920. doi:10.1016/j.psyneuen.2009.12.006

London, S., Quinn, K., Scheidell, J. D., Frueh, B. C., \& Khan, M. R. (2017). Adverse experiences in childhood and sexually transmitted infection risk from adolescence into adulthood. Sexually Transmitted Diseases, 44, 524-532. doi:10.1097/olq.0000000000000640 
Luo, R., Xu, L., Zhao, W., Ma, X., Xu, X., Kou, J., ... Kendrick, K. M. (2017). Oxytocin facilitation of acceptance of social advice is dependent upon the perceived trustworthiness of individual advisors. Psychoneuroendocrinology, 83, 1-8. doi:10.1016/j.psyneuen.2017.05.020

MacKinnon, S. L., \& Boon, S. D. (2012). Protect the individual or protect the relationship? A dualfocus model of indirect risk exposure, trust, and caution. Journal of Social and Personal Relationships, 29, 262-283. doi:10.1177/0265407511431178

Marshall, T. C., Bejanyan, K., Di Castro, G., \& Lee, R. A. (2013). Attachment styles as predictors of Facebook-related jealousy and surveillance in romantic relationships. Personal Relationships, 20, 122. doi:10.1111/j.1475-6811.2011.01393.x

Masaro, C. L., Dahinten, V. S., Johnson, J., Ogilvie, G., \& Patrick, D. M. (2008). Perceptions of sexual partner safety. Sexually Transmitted Diseases, 35, 566-571.

doi:10.1097/OLQ.0b013e3181660c43

Matson, P. A., Chung, S. S., Huettner, S. B. S., \& Ellen, J. M. M. D. (2014). Understanding variability in adolescent women's sexually transmitted infection-related perceptions and behaviors associated with main sex partners. Sexually Transmitted Diseases, 41, 475-479. doi:10.1097/OLQ.0000000000000163

Matson, P. A., Fortenberry, J. D., Chung, S.-E., Gaydos, C. A., \& Ellen, J. M. (2018). Weekly variations in feelings of trust predict incident STI within a prospective cohort of adolescent women from a US city. Sexually Transmitted Infections. doi:10.1136/sextrans-2017-053431

McBride, K. R., \& Fortenberry, J. D. (2010). Heterosexual anal sexuality and anal sex behaviors: A review. Journal of Sex Research, 47, 123-136. doi:10.1080/00224490903402538 
McCarthy, M. H., Wood, J. V., \& Holmes, J. G. (2017). Dispositional pathways to trust: Self-esteem and agreeableness interact to predict trust and negative emotional disclosure. Journal of Personality and Social Psychology, 113, 95-116. doi:10.1037/pspi0000093

McKee, A. (2016). Pornography as a creative industry: Challenging the exceptionalist approach to pornography. Porn Studies, 3, 107-119. doi:10.1080/23268743.2015.1065202

McNair, R. P., Hegarty, K., \& Taft, A. (2012). From silence to sensitivity: A new identity disclosure model to facilitate disclosure for same-sex attracted women in general practice consultations. Social Science \& Medicine, 75, 208-216. doi:10.1016/j.socscimed.2012.02.037

Meston, C. M., \& Buss, D. M. (2007). Why humans have sex. Archives of Sexual Behavior, 36, 477507. doi:10.1007/s10508-007-9175-2

Michael, F. (2003). Lust, trust and latex: Why young heterosexual men do not use condoms. Culture, Health \& Sexuality, 5, 353-369. doi:10.1080/1369105011000028273

Mikulincer, M. (1998). Attachment working models and the sense of trust: An exploration of interaction goals and affect regulation. Journal of Personality and Social Psychology, 74, 1209-1224. doi:10.1037/0022-3514.74.5.1209

Mikulincer, M., \& Shaver, P. R. (2005). Attachment theory and emotions in close relationships: Exploring the attachment-related dynamics of emotional reactions to relational events. Personal Relationships, 12, 149-168. doi:10.1111/pere.2005.12.issue-2

Mitchell, J. W. (2016). Differences in relationship characteristics between HIV-negative male couples who used and did not use substances with sex. AIDS \& Behavior, 20, 667-678. doi:10.1007/s10461015-1148-1 
Mitchell, J. W., Champeau, D., \& Harvey, S. M. (2013). Actor-partner effects of demographic and relationship factors associated with HIV risk within gay male couples. Archives of Sexual Behavior, 42, 1337-1345. doi:10.1007/s10508-012-9985-8

Mitchell, J. W., Harvey, S. M., Champeau, D., Moskowitz, D. A., \& Seal, D. W. (2012). Relationship factors associated with gay male couples' concordance on aspects of their sexual agreements:

Establishment, type, and adherence. AIDS \& Behavior, 16, 1560-1569. doi:10.1007/s10461-011$0064-2$

Mitchell, J. W., Lee, J. Y., Woodyatt, C., Bauermeister, J., Sullivan, P., \& Stephenson, R. (2016). Perceived challenges and rewards of forming a sexual agreement among HIV-negative male couples. Archives of Sexual Behavior, 45, 1525-1534. doi:10.1007/s10508-016-0701-y

Mitchell, J. W., \& Petroll, A. E. (2013). Factors associated with men in HIV-negative gay couples who practiced UAI within and outside of their relationship. AIDS \& Behavior, 17, 1329-1337. doi:10.1007/s10461-012-0255-5

Mmari, K., Marshall, B., Lantos, H., \& Blum, R. W. (2016). Who adolescents trust may impact their health: Findings from Baltimore. Journal of Urban Health, 93, 468-478. doi:10.1007/s11524-0160038-9

Moreno, M. A., Brockman, L. N., Wasserheit, J. N., \& Christakis, D. A. (2012). A pilot evaluation of older adolescents' sexual reference displays on Facebook. Journal of Sex Research, 49, 390-399. doi:10.1080/00224499.2011.642903

Mowlabocus, S., Harbottle, J., \& Witzel, C. (2014). What we can't see? Understanding the representations and meanings of UAI, barebacking, and semen exchange in gay male pornography. Journal of Homosexuality, 61, 1462-1480. doi:10.1080/00918369.2014.928581 
Muise, A., Giang, E., \& Impett, E. A. (2014). Post sex affectionate exchanges promote sexual and relationship satisfaction. Archives of Sexual Behavior, 43, 1391-1402. doi:10.1007/s10508-014-03053

Mullinax, M., Sanders, S., Dennis, B., Higgins, J., Fortenberry, J. D., \& Reece, M. (2016a). How condom discontinuation occurs: Interviews with emerging adult women. Journal of Sex Research, 54, 642-650. doi:10.1080/00224499.2016.1143440

Mullinax, M., Sanders, S., Higgins, J., Dennis, B., Reece, M., \& Fortenberry, J. D. (2016b).

Establishment of safety paradigms and trust in emerging adult relationships. Culture, Health \& Sexuality, 18(8), 890-904. doi:10.1080/13691058.2016.1148779

Murray, C. C., Hatfield-Timajchy, K., Kraft, J. M., Bergdall, A. R., Habel, M. A., Kottke, M., \& Diclemente, R. J. (2013). In their own words: Romantic relationships and the sexual health of young African American women. Public Health Reports, 128(Suppl 1), 33-42.

doi:10.1177/00333549131282S104

Murray, S. L., Aloni, M., Holmes, J. G., Derrick, J. L., Stinson, D. A., \& Leder, S. (2009). Fostering partner dependence as trust insurance: The implicit contingencies of the exchange script in close relationships. Journal of Personality and Social Psychology, 96, 324-348. doi:10.1037/a0012856

Murray, S. L., Bellavia, G. M., Rose, P., \& Griffin, D. W. (2003). Once hurt, twice hurtful: How perceived regard regulates daily marital interactions. Journal of Personality and Social Psychology, 84, 126-147. doi:10.1037/0022-3514.84.1.126

Murray, S. L., Derrick, J. L., Leder, S., \& Holmes, J. G. (2008). Balancing connectedness and selfprotection goals in close relationships: A levels-of-processing perspective on risk regulation. Journal of Personality and Social Psychology, 94, 429-459. doi:10.1037/0022-3514.94.3.429 
Murray, S. L., Gomillion, S., Holmes, J. G., Harris, B., \& Lamarche, V. (2013). The dynamics of relationship promotion: Controlling the automatic inclination to trust. Journal of Personality and Social Psychology, 104, 305-334. doi:10.1037/a0030513

Murray, S. L., Holmes, J. G., Griffin, D. W., \& Derrick, J. L. (2015). The equilibrium model of relationship maintenance. Journal of Personality and Social Psychology, 108, 93-113. doi: $10.1037 / \mathrm{pspi0} 000004$

Murray, S. L., Lupien, S. P., \& Seery, M. D. (2012). Resilience in the face of romantic rejection: The automatic impulse to trust. Journal of Experimental Social Psychology, 48, 845-854.

doi:10.1016/j.jesp.2012.02.016

Murray, S. L., Pinkus, R. T., Holmes, J. G., Harris, B., Gomillion, S., Aloni, M., ... Leder, S. (2011). Signaling when (and when not) to be cautious and self-protective: Impulsive and reflective trust in close relationships. Journal of Personality and Social Psychology, 101, 485-502. doi:10.1037/a0023233

Nadal, K. L., Davidoff, K. C., Davis, L. S., \& Wong, Y. (2014). Emotional, behavioral, and cognitive reactions to microaggressions: Transgender perspectives. Psychology of Sexual Orientation and Gender Diversity, 1, 72-81. doi:10.1037/sgd0000011

National Research Council. (1987). Risking the future: Adolescent sexuality, pregnancy, and childbearing. (C. D. Hayes Ed.). Washington, DC: The National Academies Press.

Norona, J. C., Welsh, D. P., Olmstead, S. B., \& Bliton, C. F. (2017). The symbolic nature of trust in heterosexual adolescent romantic relationships. Archives of Sexual Behavior, 46, 1673-1684. doi:10.1007/s10508-017-0971-z

Norris, S. L., \& Zweigenhaft, R. L. (1999). Self-monitoring, trust, and commitment in romantic relationships. The Journal of Social Psychology, 139, 215-220. doi:10.1080/00224549909598375 
Parker, C. M., Parker, R. G., Philbin, M. M., \& Hirsch, J. S. (2018). The impact of urban US policing practices on Black men who have sex with men's HIV vulnerability: Ethnographic findings and a conceptual model for future research. Journal of Urban Health, 95, 171-178. doi:10.1007/s11524017-0220-8

Pascuzzo, K., Cyr, C., \& Moss, E. (2013). Longitudinal association between adolescent attachment, adult romantic attachment, and emotion regulation strategies. Attachment \& Human Development, 15, 83-103. doi:10.1080/14616734.2013.745713

Philliber, S., Namerow, P. B., Kaye, J. W., \& Kunkes, C. H. (1986). Pregnancy risk taking among adolescents. Journal of Adolescent Research, 1, 463-481. doi:10.1177/074355488614011

Platt, L. F., \& Lenzen, A. L. (2013). Sexual orientation microaggressions and the experience of sexual minorities. Journal of Homosexuality, 60, 1011-1034. doi:10.1080/00918369.2013.774878

Prestage, G., Hurley, M., \& Brown, G. (2013). “Cum play” among gay men. Archives of Sexual Behavior, 42, 1347-1356. doi:10.1007/s10508-013-0074-4

Puts, D. A., Jones, B. C., \& DeBruine, L. M. (2012). Sexual selection on human faces and voices. Journal of Sex Research, 49, 227-243. doi:10.1080/00224499.2012.658924

Reimann, M., Schilke, O., \& Cook, K. S. (2017). Trust is heritable, whereas distrust is not. PNAS Proceedings of the National Academy of Sciences of the United States of America, 114, 7007-7012. doi:10.1073/pnas.1617132114

Reiss, I. L. (1970). Premarital sex as deviant behavior: An application of current approaches to deviance. American Sociological Review, 35, 78-87.

Rempel, J. K., Holmes, J. G., \& Zanna, M. P. (1985). Trust in close relationships. Journal of Personality and Social Psychology, 49, 95-112. doi:10.1037/0022-3514.49.1.95 
Rempel, J. K., Ross, M., \& Holmes, J. G. (2001). Trust and communicated attributions in close relationships. Journal of Personality and Social Psychology, 81, 57-64.

Rice, E., Craddock, J., Hemler, M., Rusow, J., Plant, A., Montoya, J., \& Kordic, T. (2018).

Associations between sexting behaviors and sexual behaviors among mobile phone-owning teens in Los Angeles. Child Development, 89, 110-117. doi:10.1111/cdev.12837

Richters, J., de Visser, R. O., Rissel, C. E., Grulich, A. E., \& Smith, A. M. A. (2008). Demographic and psychosocial features of participants in bondage and discipline, 'sadomasochism' or dominance and submission (BDSM): Data from a national survey. Journal of Sexual Medicine, 5, 1660-1668. doi:10.1111/j.1743-6109.2008.00795.x

Riedl, R., Javor, A., Gefen, D., Felten, A., \& Reuter, M. (2017). Oxytocin, trust, and trustworthiness: The moderating role of music. Journal of Neuroscience, Psychology, and Economics, 10, 1-8. doi:10.1037/npe0000070

Robertson, A. M., Syvertsen, J. L., Amaro, H., Martinez, G., Rangel, M. G., Patterson, T. L., \& Strathdee, S. A. (2014). Can't buy my love: A typology of female sex workers' commercial relationships in the Mexico-U.S. Border Region. Journal of Sex Research, 51, 711-720. doi:10.1080/00224499.2012.757283

Rodriguez, L. M., DiBello, A. M., Øverup, C. S., \& Neighbors, C. (2015). The price of distrust: Trust, anxious attachment, jealousy, and partner abuse. Partner Abuse, 6, 298-319. doi:10.1891/1946-6560.6.3.298

Rohleder, P., McDermott, D. T., \& Cook, R. (2017). Experience of sexual self-esteem among men living with HIV. Journal of Health Psychology, 22, 176-185. doi:10.1177/1359105315597053

Romer, D., Betancourt, L. M., Brodsky, N. L., Giannetta, J. M., Yang, W., \& Hurt, H. (2011). Does adolescent risk taking imply weak executive function? A prospective study of relations between 
working memory performance, impulsivity, and risk taking in early adolescence. Developmental Science, 14, 1119-1133. doi:10.1111/j.1467-7687.2011.01061.x

Rosenthal, L., \& Starks, T. J. (2015). Relationship stigma and relationship outcomes in interracial and same-sex relationships: Examination of sources and buffers. Journal of Family Psychology, 29, 818830. doi:10.1037/fam0000116

Rotter, J. B. (1967). A new scale for the measurement of interpersonal trust. Journal of Personality, 35, 651-665. doi:10.1111/j.1467-6494.1967.tb01454.x

Rousseau, D. M., Sitkin, S. B., Burt, R. S., \& Camerer, C. (1998). Not so different after all: A crossdiscipline view of trust. Academy of Management Review, 23, 393-404.

doi:10.5465/amr.1998.926617

Rubel, A. N., \& Bogaert, A. F. (2015). Consensual nonmonogamy: Psychological well-being and relationship quality correlates. Journal of Sex Research, 52, 961-982.

doi:10.1080/00224499.2014.942722

Schilder, A. J., Orchard, T. R., Buchner, C. S., Miller, M. L., Fernandes, K. A., Hogg, R. S., \& Strathdee, S. A. (2008). 'It's like the treasure': Beliefs associated with semen among young HIVpositive and HIV-negative gay men. Culture, Health \& Sexuality, 10, 667-679.

doi:10.1080/13691050802183899

Senior, K., Helmer, J., Chenhall, R., \& Burbank, V. (2014). 'Young clean and safe?' Young people's perceptions of risk from sexually transmitted infections in regional, rural and remote Australia. Culture, Health \& Sexuality, 16, 453-466. doi:10.1080/13691058.2014.888096

Shin, D.-H. (2010). The effects of trust, security and privacy in social networking: A security-based approach to understand the pattern of adoption. Interacting with Computers, 22, 428-438.

doi:10.1016/j.intcom.2010.05.001 
Short, E., Brown, A., Pitchford, M., \& Barnes, J. (2017). Revenge porn: Findings from the Harassment and Revenge Porn (HARP) survey_Preliminary results. Annual Review of CyberTherapy and Telemedicine, 15, 161-166.

Simpson, J. A. (2007). Psychological foundations of trust. Current Directions in Psychological Science, 16, 264-268. doi:10.1111/j.1467-8721.2007.00517.x

Smith, C., Cook, R., \& Rohleder, P. (2017). Taking into account the quality of the relationship in HIV disclosure. AIDS \& Behavior, 21, 106-117. doi:10.1007/s10461-016-1323-z

Smith, F. G., Jones, B. C., Little, A. C., DeBruine, L. M., Welling, L. L. M., Vukovic, J., \& Conway, C. A. (2009). Hormonal contraceptive use and perceptions of trust modulate the effect of relationship context on women's preferences for sexual dimorphism in male face shape. Journal of Evolutionary Psychology, 7, 195-210. doi:10.1556/JEP.7.2009.3.1

Sofer, C., Dotsch, R., Oikawa, M., Oikawa, H., Wigboldus, D. H. J., \& Todorov, A. (2017). For your local eyes only: Culture-specific face typicality influences perceptions of trustworthiness. Perception, 46, 914-928. doi:10.1177/0301006617691786

Stanton, S. C. E., Campbell, L., \& Pink, J. C. (2017). Benefits of positive relationship experiences for avoidantly attached individuals. Journal of Personality and Social Psychology, 113, 568-588. doi: $10.1037 / \mathrm{pspi0000098}$

Starks, T. J., Castro, M. A., Castiblanco, J. P., \& Millar, B. M. (2017). Modeling interpersonal correlates of condomless anal sex among gay and bisexual men: An application of attachment theory. Archives of Sexual Behavior, 46, 1089-1099. doi:10.1007/s10508-016-0851-y

Stevens, P. E., \& Hall, J. M. (2001). Sexuality and safer sex: The issues for lesbians and bisexual women. JOGNN - Journal of Obstetric, Gynecologic, \& Neonatal Nursing, 30, 439-447. doi:10.1111/j.1552-6909.2001.tb01563.x 
Stirrat, M., \& Perrett, D. I. (2010). Valid facial cues to cooperation and trust: Male facial width and trustworthiness. Psychological Science, 21, 349-354. doi:10.1177/0956797610362647

Strachman, A., \& Impett, E. A. (2009). Attachment orientations and daily condom use in dating relationships. Journal of Sex Research, 46, 319-329. doi:10.1080/00224490802691801

Sullivan, T. J., Feinstein, B. A., Marshall, A. D., \& Mustanski, B. (2017). Trauma exposure, discrimination, and romantic relationship functioning: A longitudinal investigation among LGB young adults. Psychology of Sexual Orientation and Gender Diversity, 4, 481-490. doi:10.1037/sgd0000249

Syvertsen, J. L., Bazzi, A. R., Martinez, G., Rangel, M. G., Ulibarri, M. D., Fergus, K. B., ... Strathdee, S. A. (2015). Love, trust, and HIV risk among female sex workers and their intimate male partners. American Journal of Public Health, 105, 1667-1674. doi:10.2105/AJPH.2015.302620

Syvertsen, J. L., Robertson, A. M., Palinkas, L. A., Rangel, M. G., Martinez, G., \& Strathdee, S. A. (2013). 'Where sex ends and emotions begin': Love and HIV risk among female sex workers and their intimate, non-commercial partners along the Mexico-US border. Culture, Health \& Sexuality, 15, 540-554. doi:10.1080/13691058.2013.773381

Syvertsen, J. L., Robertson, A. M., Rolon, M. L., Palinkas, L. A., Martinez, G., Rangel, M. G., \& Strathdee, S. A. (2013). “Eyes that don't see, heart that doesn't feel”: Coping with sex work in intimate relationships and its implications for HIV/STI prevention. Social Science \& Medicine, 87, 18. doi:10.1016/j.socscimed.2013.03.010

Szielasko, A. L., Symons, D. K., \& Price, E. L. (2013). Development of an attachment-informed measure of sexual behavior in late adolescence. Journal of Adolescence, 36, 361-370. doi:10.1016/j.adolescence.2012.12.008 
Thompson, A. E., \& O’Sullivan, L. F. (2016). Drawing the line: The development of a comprehensive assessment of infidelity judgments. Journal of Sex Research, 53, 910-926.

doi:10.1080/00224499.2015.1062840

Towner, S. L., Dolcini, M. M., \& Harper, G. W. (2015). Romantic relationship dynamics of urban African American adolescents. Youth \& Society, 47, 343-373. doi:10.1177/0044118x12462591

Træen, B., \& Gravningen, K. (2011). The use of protection for sexually transmitted infections (STIs) and unwanted pregnancy among Norwegian heterosexual young adults 2009. Sexuality \& Culture: An Interdisciplinary Quarterly, 15, 195-212. doi:10.1007/s12119-011-9090-5

Trub, L., \& Starks, T. J. (2017). Insecure attachments: Attachment, emotional regulation, sexting and condomless sex among women in relationships. Computers in Human Behavior, 71, 140-147. doi:10.1016/j.chb.2017.01.052

Underhill, K., Dumont, D., \& Operario, D. (2014). HIV prevention for adults with criminal justice involvement: A systematic review of HIV risk-reduction interventions in incarceration and community settings. American Journal of Public Health, 104, e27-e53.

doi:10.2105/AJPH.2014.302152

Uysal, A., Lin, H. L., \& Bush, A. L. (2012). The reciprocal cycle of self-concealment and trust in romantic relationships. European Journal of Social Psychology, 42, 844-851. doi:10.1002/ejsp.1904

van Anders, S. M., Edelstein, R. S., Wade, R. M., \& Samples-Steele, C. R. (2013). Descriptive experiences and sexual vs. nurturant aspects of cuddling between adult romantic partners. Archives of Sexual Behavior, 42, 553-560. doi:10.1007/s10508-012-0014-8

van Anders, S. M., Goodson, J. L., \& Kingsbury, M. A. (2013). Beyond 'oxytocin = good': Neural complexities and the flipside of social bonds. Archives of Sexual Behavior, 42, 1115-1118. doi:10.1007/s10508-013-0134-9 
van Hooff, J. (2017). An everyday affair: Deciphering the sociological significance of women's attitudes towards infidelity. Sociological Review, 65, 850-864. doi:10.1111/1467-954X.12417

Van Ouytsel, J., Van Gool, E., Walrave, M., Ponnet, K., \& Peeters, E. (2016). Exploring the role of social networking sites within adolescent romantic relationships and dating experiences. Computers in Human Behavior, 55(Part A), 76-86. doi:10.1016/j.chb.2015.08.042

Velten, J., \& Brotto, L. A. (2017). Interoception and sexual response in women with low sexual desire. PLoS ONE [Electronic Resource], 12, e0185979. doi:10.1371/journal.pone.0185979

Vukovic, J., Jones, B. C., Feinberg, D. R., DeBruine, L. M., Smith, F. G., Welling, L. L. M., \& Little, A. C. (2011). Variation in perceptions of physical dominance and trustworthiness predicts individual differences in the effect of relationship context on women's preferences for masculine pitch in men's voices. British Journal of Psychology, 102, 37-48. doi:10.1348/000712610X498750

Walker, D. P., DeNardi, K. A., Messman-Moore, T. L., \& Rose, A. M. (2007). Ascribing meaning to the first time: Examining metaphors of virginity. Sex Roles, 57, 933-935. doi:10.1007/s11199-0079294-1

Watkins, S. J., \& Boon, S. D. (2016). Expectations regarding partner fidelity in dating relationships. Journal of Social and Personal Relationships, 33, 237-256. doi:10.1177/0265407515574463

Weisskirch, R. S., \& Delevi, R. (2011). 'Sexting' and adult romantic attachment. Computers in Human Behavior, 27, 1697-1701. doi:10.1016/j.chb.2011.02.008

Weisskirch, R. S., Drouin, M., \& Delevi, R. (2017). Relational anxiety and sexting. Journal of Sex Research, 54, 685-693. doi:10.1080/00224499.2016.1181147

Willig, C. (1997). The limitations of trust in intimate relationships: Constructions of trust and sexual risk taking. British Journal of Social Psychology, 36, 211-221. 
Zablotska, I. B., Grulich, A. E., De Wit, J., \& Prestage, G. (2011). Casual sexual encounters among gay men: Familiarity, trust and unprotected anal intercourse. AIDS and Behavior, 15, 607-612. doi:10.1007/s10461-010-9675-2

Zak, A., \& McDonald, C. (1997). Satisfaction and trust in intimate relationships: Do lesbians and heterosexual women differ? Psychological Reports, 80, 904-906. doi:10.2466/pr0.1997.80.3.904

Zak, P. J., Kurzban, R., \& Matzner, W. T. (2004). The neurobiology of trust. Annals of the New York Academy of Sciences, 1032, 224-227. doi:10.1196/annals.1314.025

Zhang, N., Abler, L., Bao, Y., \& Pan, S. (2014). Understanding the meaning of short-term, yiyeqing relationships and how they are formed: Implications for condom use in Liuzhou, China. AIDS \& Behavior, 18(Suppl 2), S126-134. doi:10.1007/s10461-013-0489-x

Zhong, S., Monakhov, M., Mok, H. P., Tong, T., Lai, P. S., Chew, S. H., \& Ebstein, R. P. (2012). Ushaped relation between plasma oxytocin levels and behavior in the trust game. PLoS ONE, 7, e51095. doi:10.1371/journal.pone.0051095

Zhuang, J. Y., Zhang, S., Xu, J., \& Hu, D. (2014). Discriminating males and unpredictable females: Males differentiate self-similar facial cues more than females in the judgment of opposite-sex attractiveness. PLoS ONE, 9, e90493. doi:10.1371/journal.pone.0090493

Zwane, I. T., Mngadi, P. T., \& Nxumalo, M. P. (2004). Adolescents' views on decision-making regarding risky sexual behaviour. International Nursing Review, 51, 15-22. doi:10.1111/j.14667657.2003.00214.x 